\title{
Collaborative Language Pedagogy And Students' Academic Achievement In English Language In Ekiti State
}

\author{
J. O. Babalola, (Ph. D) \\ Arts and Language Education Department, \\ Faculty of Education Ekiti State University, Ado-Ekiti \\ F. I. Agbaje \\ Arts and Language Education Department \\ Faculty of Education Ekiti State University, Ado-Ekiti
}

\begin{abstract}
This study examined the effect of collaborative teaching on students' academic achievement in English language in Ekiti State. The population consisted of 161 Junior Secondary school three students made up of 103 males and 58 females selected from Federal Science and Technical College, Usi-Ekiti, Ekiti State. A total of 20 students (10 males) and (10 females) randomly selected from the school constituted the sample. The twenty students were divided into two groups-Experimental and Control. Group A was used as experimental group while group B was used as the control group. Two research questions and two hypotheses guided the study. The data collected were analysed using mean and percentages to answer the research questions while t-test and chi-square statistics were used to test the hypotheses. The major findings show that the students taught with Collaborative Teaching Strategy (CTS) achieved significantly better outputs than those of the control group. The study also discovered that there was no significant gender difference in the students' achievement in English language. Based on the findings of this study, it was recommended that collaborative teaching strategy should be adopted as a more effective approach to teaching of English Language at the Junior Secondary School levels.
\end{abstract}

Keywords: Teaching, Collaborative Strategy, Single Teaching Strategy, Curriculum, Achievement.

\section{INTRODUCTION}

Language is a peculiar human attribute for communication. Devaloe (2014) asserts that language impacts the daily lives of members of any race, creed and region of the world. It helps to express one's feelings, desires, attitudes and perceptions to the world around us. According to Babalola and Oyinloye (2012) language gives a unique distinction to a person, a sex, a group (as in different professions, assemblies etc) and a nation. Language is an innate power of communicating ideas, feelings and desires by means of systems of sound and symbols (Ezeude, 2007). Thus, its role in human existence is most noticeable in educational industry (Igbokwe and Egbe, 2011). Classroom interactions, discussions and activities would be impossible without language. English language being one of the leading and major languages in the world, it is widely used all over the globe (Singh, 2007). It is the language of international, political, industrial and diplomatic relations among many countries of the world. English may not be the most spoken language in the world but recent data show that there are 55 sovereign states and 27 non-sovereign entities where English was an official language (Wikipedia, 2019).

In Nigeria, English is the official language used to carry out day to day government activities. Evue (2013) discovers that, English language is so central to Nigeria's educational growth 
because of its significant role as a medium of knowledge delivery at every level of education. As a result of this, the Federal Government of Nigeria in the National Policy on Education (FGN, 2014) recommends English language as a medium of instruction at all levels of education in Nigeria.

English language teaching and learning has various aspects (Speech, Comprehension, Grammar/Syntax, Mechanics and Essay writing) through which students are expected to have a considerable mastery for sound academic achievement. The teachers' task in public secondary schools is to teach all the aspects of English language and assess students by giving tests, assignments and projects with the aim of providing feedback. Teachers equally set examination questions, mark and record them as well. Thus, the workload of teachers and their varying professional skills in all aspects of English language could compel them to give more time to some aspects of the language than the others which could be a serious disadvantage to the students. One way to address this ugly trend may be to give a trial to Collaborative Teaching (CT) as an alternative strategy to teaching that goes beyond the traditional practice of Single Teacher Teaching Strategy (STTS) in secondary schools.

An alternative teaching strategy-Collaborative Teaching (CT) is different from Single Teacher Teaching (STT) because it involves two or more teachers each with distinctive roles, sharing responsibilities for planning, presentation and evaluation of lessons for the same group of students. Wadkins, Wozniak and Miller (2004) declare that strategy such as CT has the advantages of creating additional time for other academic activities in the school and supportive learning environment which will give the opportunity for intellectual growth, as well as increasing student-teacher interactions. This will also overcome isolation that is the norm in the conventional single teaching approach (Wadkins, et al, 2004). Collaborative teaching involves distribution of responsibilities among people for planning, instruction and evaluation for a classroom of students. Hourcade and Bauwens (2002) argue that when teachers collaborate, they have an opportunity to capitalize upon unique and specialized knowledge and skills of their colleagues. This is the position of Du Four (2003) who defines collaborative teaching as a systematic process where teachers work together to analyse and impact professional practice for the improvement of individual and collective students' better outputs. CT is a symbiotic relationship among the collaborating teachers and the learners. The teachers benefit from one another. The learners equally benefit from the collaborative teaching. This is the position of Bunker and Vescio (2008) that educators' collaboration plays significant role in improving the academic outcomes of the students. According to Bess (2000), all members in the team are equally involved and responsible for students' instruction, assessment and the setting and meeting of learning objectives.

In relation to this study, $\mathrm{CT}$ is a process whereby the different components of English language at the Junior Secondary School level such as Speech, Comprehension /Vocabulary Development, Grammar/Syntax, Mechanics and Essay writing are structured in such a way that different teachers (experts) handle each part to enhance optimum achievement by students. This strategy can best be described as "Hand Approach Strategy" (HAS) or Five- Finger Approach (FFA).This is illustrated in figure 1: 


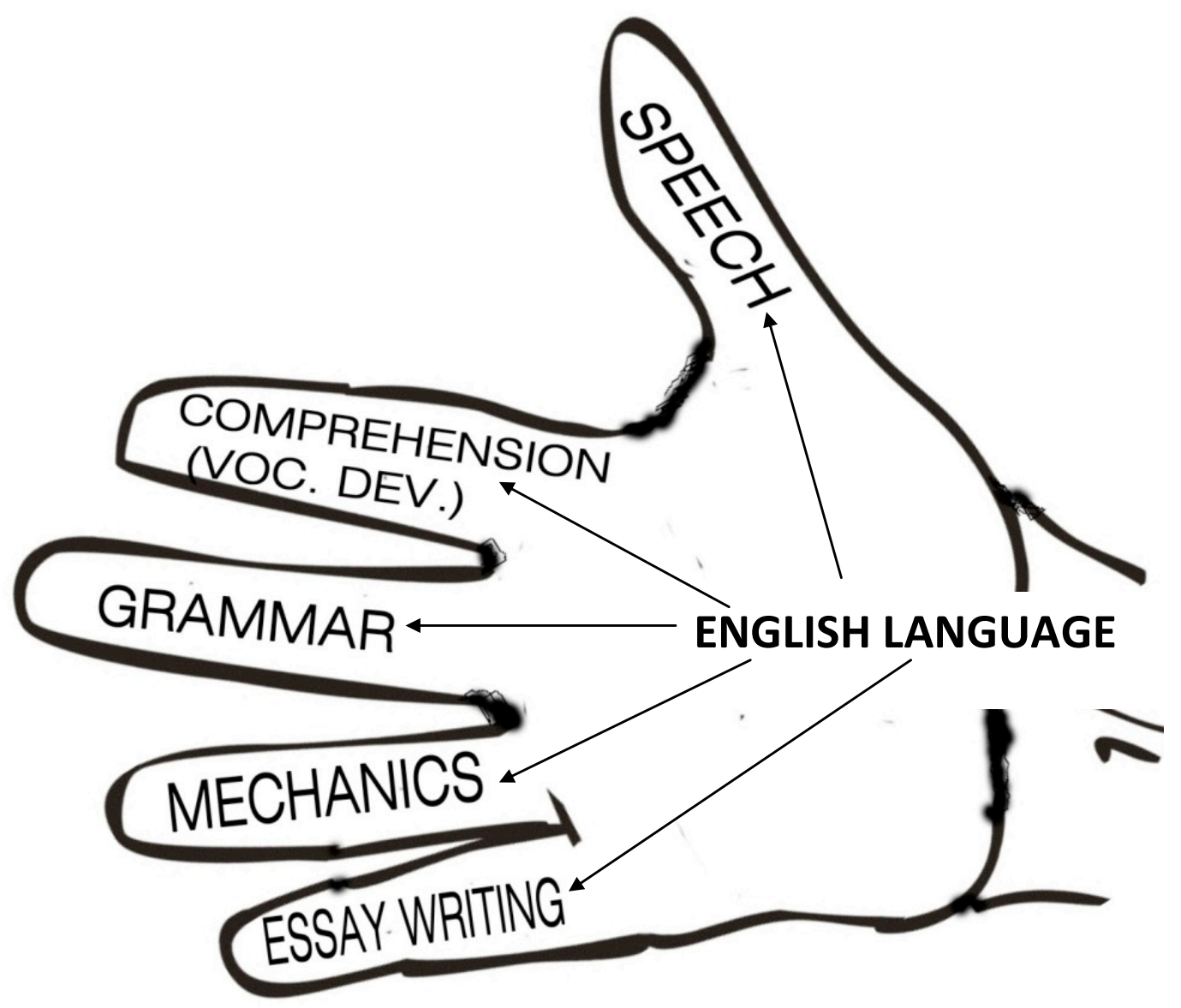

Voc. Dev: Vocabulary Development

Fig. 1: Hand Approach Strategy (HAS) or Five- Finger Approach (FFA)

In a school system, the five aspects of English language are expected to be spelt out into different periods per week from Monday to Friday viz:

1. Monday - Speech Work

2. Tuesday - Comprehension/Vocabulary Development

3. Wednesday- Grammar/Syntax

4. Thursday- Mechanics

5. Friday- Essay Writing /Continuous Writing.

The five periods per week on the time table for English language is conventional in most schools. It is a laid down procedure as contained in the National Policy on Education (FGN, 2014). Thus, the five components of English Language therefore follow the different skills (listening, speaking, reading and writing) through which a learner learns a language. It is incumbent on the teacher to teach all the aspects of English language: Speech, Comprehension /Vocabulary Development, Grammar/Syntax, Mechanics and Essay writing scheduled on the school timetable in each class every week.

Although, collaborative teaching has its demerits of exposing students to a variety of teaching styles and approaches, which could increase various learning needs of students, some students may feel frustrated and discontented about having more than one teacher. Collaborative teaching could become a distraction if the teachers involved are not focused on students' 
learning and achievements. That is, if the teaching is not learner-centered. However, with proper collaboration and cohesiveness within a team, there are vital benefits for those willing to adopt collaborative teaching. When English language teachers come together to share information, resources and expertise, learning becomes more accessible and effective for students. Collaborative teaching enhances interpersonal relationship among teachers and improves on the learning ability of students. Harati (2012) believes teachers play enormous role on the opportunity to work together as a team to improve learning outcome.

Several researchers have classified collaborative teaching into models and categories. Leavett (2006) identifies three models of collaborative teaching which are interactive, rotational and dispersed models. Goetz (2000) classifies collaborative teaching into; Category A and B. In category A, two or more instructors are teaching the same students at the same time within the same classroom. While in category B, the instructors work together but do not necessarily teach the same group of students nor necessarily teach at the same time. In this study however, Goetz (2000) category 'A' was used.

There is an assumption by some researchers that gender could influence learning of English language. Consequently, Murni (2018) in a research on gender differences in English language teaching at Universitas Negeri Makassar, Indonesia concludes that gender differences are important aspect to be considered in English language teaching. However, the extent to which knowledge is dependent on gender appears not to be resolved yet. Some authorities such as (Eze, 2000; Gbodi and Laleye 2006) believe that good teaching should break the boundaries of gender .This is in line with the postulate of Babalola and Oyinloye (2012) that the concept that one sex naturally performs better than the other should be cast off. But Opara, (2001) opines that knowledge is gender-related.

The students' academic achievement in secondary schools in English language has been worrisome and there are various concerns from general public on this worsened academic achievement. The poor performance of students particularly in Basic Education Certificate Examination (BECE) in English language over the years is of great concern to both linguists and educators. The perception on poor academic achievement in English language is that the single teacher teaching strategy might have been partly responsible for students continued poor academic achievement.

Abdullah and Ömer (2018) use a meta- analysis study to examine the effect of collaborative learning approach on students' academic achievement in Turkish, Turkey. Thirty two (32) researches examining the effect of collaborative learning approach on the academic achievement in Turkish courses of students studying in Turkey and providing the criteria determined for the study were included in meta-analysis. It was found out that collaborative learning approach has positive effect on academic achievement of the students in Turkish courses in comparison with traditional methods.

In another study, Ervin (2011) investigates the relationship between teacher collaboration and student achievement in reading, Language Arts and Mathematics. A 37-item attitudinal perception survey was used as the instrument of the study. Three variables: level of teacher collaboration, level of administrative support and time collaboration, were created from the teachers' responses to the items by obtaining the mean of the responses on a 5-point Likert scale. Student Grades 3, 5, and 7 scores were used to measure students' achievements. Results from a multiple regression analyses show that level of teacher collaboration was not a significant predictor of achievement but that level of administrator's support and time of collaboration were significant predictors of teacher collaboration. 
In Nigeria, particularly in Ekiti State, collaborative teaching strategy is still unpopular. More importantly, no known study has been established on the effect of collaborative teaching on junior secondary school academic achievement in English language in Ekiti State. Thus, this study focuses on the effect of collaborative teaching on students' academic achievement in junior secondary school students in Ekiti State.

\section{Statement of the Problem}

Students' performance in English language especially in various external examinations organized in Nigeria is poor in spite of its importance in the school curriculum. This trend which has been noticeable over the years has continued to get worse which is of great concern to educators and the general public. There is the need to give prompt and serious attention to address the present anomaly in the teaching and learning of English language. If the conventional method of single teacher teaching strategy has failed to yield positive result, there is the need to consider another strategy such as collaborative teaching which could be of immense assistance to both the teachers and the learners. The focus of this work therefore is to determine the effect of collaborative teaching on English language academic achievement and the extent to which the achievement varies among gender.

\section{Purpose of the Study}

The purpose of this study is to:

1. determine the English language mean achievement scores of students taught with collaborative teaching strategy(CTS) and those taught with single teacher teaching strategy (STTS).

2. examine the English language achievement scores of male and female students taught with CTS and those taught with STTS.

\section{Research Questions}

The following research questions guided the study:

1. What is the English language mean achievement scores of students taught with collaborative teaching strategy (CTS) and those taught with single teacher teaching strategy (STTS)?

2. What is the English language achievement scores of male and female students taught with CTS and those taught with STTS?

\section{Research Hypotheses}

The following hypotheses were postulated for the study:

1. There is no significant difference between the English language mean achievement scores of junior secondary school three students taught with CTS and those taught with STTS.

2. There is no significant difference in English language achievement scores of male and female students taught with CTS and those taught with STTS.

\section{METHODOLOGY}

The study adopted quasi-experimental design. The population consists of one hundred and sixty one (161) Junior Secondary School Three (JSS III) students of Federal Science and Technical College, Usi-Ekiti, Ekiti State. A total of twenty (20) students (10 males and 10 females) randomly selected from the JSS III classes in the College constituted the sample. Ten of the selected students were used as experimental group while the other ten were used as the control group. The instrument used for the study was a self-designed Achievement Test. Six experienced English language teachers helped to revalidate the instrument. The collaborative teachers taught those in the experimental group with the lesson notes and materials they 
prepared together while those in the control group were taught by one teacher through a conventional method. The research questions were answered with the mean and percentage while the hypotheses were tested with t-test and chi-square statistics.

\section{RESULTS}

Research Question 1: What is the mean achievement scores in English language of students taught with CTS and those taught with STTS?

Table 1: Mean achievement scores in English language of students taught with CTS and STTS

Strategy Mean

Collaborative Teaching Strategy (CTS)

Single Teacher Teaching Strategy (STTS)

55.7

Table 1 shows mean scores of 65.6 and 55.7 for CTS group and STTS group respectively. The mean score for the CTS group was 65.6 while that of the STTS group was 55.7. This shows that students in the CTS group had a higher mean achievement score than the students in STTS group.

Research Question 2: What is the English language achievement scores of male and female students taught with CTS and those taught with STTS?

Table 2: English language achievement scores of male and female students taught with CTS and those taught with STTS

\begin{tabular}{llc} 
Strategy & \multicolumn{2}{c}{ Percentage Score } \\
& Male & Female \\
\hline Collaborative Teaching Strategy (CTS) & 66.0 & 57.6 \\
Single Teacher Teaching Strategy (STTS) & 55.4 & 56.0 \\
\hline
\end{tabular}

Table 2 shows English language achievement scores of $66.0 \%$ and $57.6 \%$ for male and female students in the CTS group. The male students have a percentage of $66.0 \%$ which is slightly higher than their female counterparts (57.6\%). In the STTS group, male students have score of $55.4 \%$ which is lower than that of their female counterparts $(56.0 \%)$ although with small margin.

Research Hypothesis 1: There is no significant difference between English language mean achievement scores of junior secondary three students taught with CTS and those taught with STTS. 
Table 3: English language mean achievement scores of students taught with collaborative teaching strategy (CTS) and single teacher teaching strategy (STTS)

\begin{tabular}{lccccccc}
\hline Strategy & $\mathrm{N}$ & Mean & SD & df & t-cal & t-cri & Decision \\
\hline CTS & 10 & 65.6 & 9.12 & & & & \\
& & & & 18 & 2.59 & 2.11 & $*$ \\
STTS & 10 & 55.7 & 7.97 & & & & \\
\hline
\end{tabular}

*Significant

As shown in table 3, the t-cal (2.59) is greater than the t-cri (2.11). Since the $t$-cal is greater than $\mathrm{t}$-cri, the null hypothesis earlier stated that there is no significant difference between the mean achievement scores in English language of junior secondary three students taught with CTS and those taught with STTS is therefore rejected. This means there is significant difference in the mean of the two groups.

Research Hypothesis 2: There is no significant difference in English language achievement scores of male and female students taught with CTS and those taught with STTS.

Table 4: English language achievement scores of male and female students taught with CTS and those taught with STTS

\begin{tabular}{lcccccc} 
Teaching Strategy & Male & Female & df & $\mathbf{X}^{2}$ cal & $\mathbf{X}^{2}$ cri & Decision \\
\hline CTS & 66 & 57.6 & & & & \\
STTS & 55.4 & 56 & & & & \\
\hline
\end{tabular}

CTS = Collaborative Teaching Strategy; STTS = Single Teacher Teaching Strategy;

NS = Not Significant.

As shown in table 4 , the $\mathrm{X}^{2}$ cri of 3.84 is greater than the $\mathrm{X}^{2}$ cal of 0.31 . Since the $\mathrm{X}^{2}$ cri is greater than $\mathrm{X}^{2}$ cal, the null hypothesis earlier stated that there is no significant difference in English language achievement scores of male and female junior secondary three students taught with CTS and those taught with STTS is hereby retained. This means that there is no gender difference in the English language achievement scores of junior secondary three students taught with CTS and those taught with STTS.

\section{DISCUSSION OF FINDINGS}

The thrust of this study is to find out whether collaborative teaching provides better students' academic achievements in English language than the single teacher teaching strategy. It is discovered that collaborative teaching provides a better academic achievement in English language. From table 1, the mean achievement score of the students taught with the collaborative teaching strategy is higher (65.6) than those taught with the single teacher teaching strategy (55.7). This result was further confirmed by the result of table 3 which indicates that the collaborative teaching strategy was a significant factor in the achievement of students in English language. 
This is shown by the rejection of the null hypothesis of no statistical difference in the mean achievement scores in English language of students taught with the collaborative teaching strategy and those taught with the single teacher teaching strategy. Thus, this result confirms that the group taught English language with CTS performed better than the group taught with STTS. This agrees with the study of Abdullahi and Omer (2018) that collaborative learning approach has positive effect on academic achievement of the students in comparison with single teacher teaching strategy. It also supports the assertion made by Wadkins, Wozniak and Miller (2004) that team-taught classes provide valuable learning experiences and increase student-teacher interaction in the class room. In contrast to this, Ervin (2011) discovers that level of teacher collaboration was not a significant predictor of achievement.

Table 4 shows the result of hypothesis 2 which indicates that gender is not a significant factor in students' achievement in English language. The result of the study concurs with the findings of Babalola and Oyinloye (2012) that male and female have equal chance of learning and acquiring tools of language apart from individuals language variations. This study is in variance with Opara (2001) who reports that females perform better in languages than the males. Also, Murni (2018) confirms that gender differences are important aspect to be considered in English language teaching.

\section{CONCLUSION}

From the results obtained from the investigation into the effects of collaborative teaching strategy on students' academic achievements in English language, the following conclusions were drawn:

The study has proved that CTS used in teaching English language is more effective than the STTS. This has therefore provided empirical basis for improving and enhancing classroom teaching and learning of English language. This is evident from the fact that the group taught with CTS performed significantly better than the group that was taught with STTS. Again, the notion that gender plays prominent role in students' achievement in the English language as a school subject is not a trendy view.

\section{RECOMMENDATIONS}

Based on the findings of this research study, the following recommendations were made: Teachers should be encouraged to adopt collaborative teaching strategy in their classroom service delivery especially now that the curriculum is broad and diverse. CTS will enable teachers to collaborate and have the opportunity to share ideas and information. It will also promote professionalism and boost the morale of teachers. The outcome of this is growth in professional expertise and rich research endeavour in specific arms of the discipline.

The adoption of collaborative teaching will help to correct students' poor attitude towards the study of English language and make teaching more participatory and interesting. Conferences, seminars and workshops should be organized by relevant government agencies for teachers to educate them on the use of collaborative teaching strategy. Equally, government should employ more English teachers to make collaborative teaching operational in all secondary schools. Enough facilities should be made available for individual teachers that collaborate to work with in the process of regular lesson delivery.

\section{References}

Abdullah, K. \& Ömer, F. T. (2018) Effect of collaborative learning approach on students' academic achievement in Turkish Courses in Turkey: A Meta-Analysis. Study Education and Science, 43, (194), 185-205.

Babalola, J. O. \& Oyinloye, G. O. (2012). Language and gender distinctions Review of Social Sciences and Humanities, 2(2), 236-242. 
Bess, J.L. (2000). Integrating autonomous professionals through team teaching in J.L. Careless, D.R. (2006). Good Practices in team teaching in Japan, South Korea and Hong Kong, System 34, 341-351.

Bunker, V. J. (2008). Professional learning communities, teacher collaboration, and student achievement in an era of standards based reform. Ann Arbor, MI: ProQuest.

Devaloes, L. (2014). Importance of Language- Why learning A second language is important. Retrieved from https://www.trinitydc.edu/continuing-education/2014/02/26/importance-of-language-why-learning-a-secondlanguage-is-important/

DuFour, R. (2003). Building a professional learning community. School Administrator, 60(5), 13-18.

Ervin, S. R. (2011). The relationship between teacher collaboration and student achievement. (Unpublished Ph.D. thesis), University of Southern Mississippi.

Retrieved from https://aquila.usm.edu/dissertations/731 on 23rd May, 2019.

Evue, A. O. (2013). Challenges facing the teaching of English language in secondary schools in Aniocha south local government area of Delta state Nigeria. African Education Indices, 5 (1),

Eze, U.N (2000). Effect of instructional and comprehensive monitoring strategies on Integrated Science achievement of junior secondary school students. Nigeria Journal of Education and Technology, 1 (1), 20-24.

Ezeude, J.I.(2007). Innovational approaches and methods in language teaching: Is Nigeria abreast of the times? In B.N. Anaisudu, G.I. Nwaozuzu and G.N. Okebalam (Eds). Language and Literature in a Developing Country. Onitsha: Africana-First Publishers Limited.

Federal Republic of Nigeria (2014).National Policy on Education. Lagos: NERDC Press.

Gbodi, B. E. \&Laleye, A. M. (2006). Effects of video-taped instruction on learning of integrated science. Journal of Research in Curriculum and Teaching, (1), 10-19.

Goetz, K. (2000). Perspectives on team teaching: A Semester 1 Independent Inquiry, A Peer Reviewed Journal, (4), $1-10$.

Hourcade, J., \& Bauwens, J. (2002). Cooperative teaching: Rebuilding and sharing the school house. Austin, TX: Pro-Ed. Retrieved from https://www.elc-schools.com/blog/4-reasons-why-learning-english-is-so-important./ Igbokwe, U.I. \& Egbe, C. I. (2011) Integrating peace education into the English language curriculum for Nigerian secondary schools. WCCI Journal of Curriculum and Instruction, 8(2),54-60.

Leavitt, M.C. (2006). Team teaching: Benefits and challenges. The Centre for Teaching and Learning. Stanford University FallNews letter, 16, 1

Main, K. \& Brye F. (2006). What does a "good" team teaching team look like in a Middle School Classroom.196 -204

Mahmud, Murni. (2018). Gender differences in English language teaching. Asian EFL Journal Professional teaching articles 20 .

Opara, F.C. (2001). Ensuring gender equity in Chemistry instruction through self-Regulation INTEJ, 3, 1

Sing,,Y. K.(2007). Teaching of English. New Dehli: APH Publishing Corporation.

Wadkins, T.; Wozniak, W. \& Miller, R.L. (2004) Team teaching models In E.G. Peck (Ed), UNK/CTE. Compendium of Teaching Resources and Ideas, 77-95 Kearney: University of Nebras

Wikipedia (2019). List of territorial entities where English is an official language.

Retrieved from https://en.wikipedia.org/wiki/ on 25 th May, 2019. 